
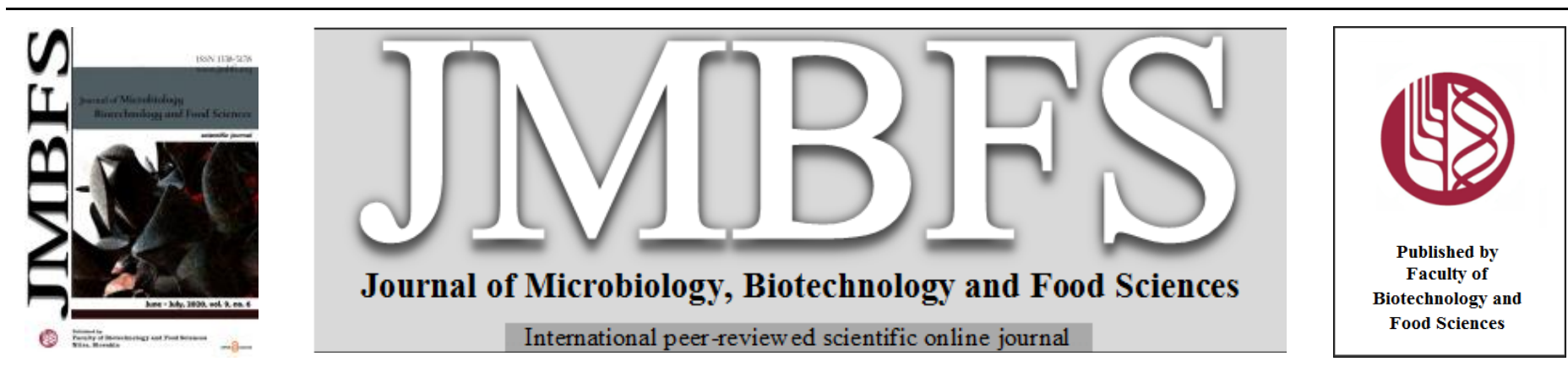

\title{
NONI (Morinda citrifolia L.) FRUIT EXTRACT POTENTIALLY MAINTAIN THE IMMUNE SYSTEM HOMEOSTASIS OF BALB/C MICE FROM DMBA AND CIGARETTE SMOKES EXPOSURE
}

\author{
Mulya Dwi Wahyuningsih ${ }^{l}$, Didin Wahyu Agustina ${ }^{l}$, Sri Widyarti ${ }^{l}$, Aris Soewondo ${ }^{l}$, Hideo Tsuboi ${ }^{2}$, Muhaimin Rifa ${ }^{*}{ }^{l}$ \\ Address(es): Prof. Muhaimin Rifa'i, S.Si., Ph.D.Med.Sc., \\ ${ }^{1}$ Department of Biology, Faculty of Mathematics and Natural Sciences, Brawijaya University, Veteran Street, Malang 65145, East Java, Indonesia. \\ ${ }^{2}$ Department of Immunology, Graduate School of Medicine, Nagoya University, Tsurumai-cho 65, Showa-ku, Nagoya 466-8550, Japan.
}

*Corresponding author: immunobiology@ub.ac.id

doi: 10.15414/jmbfs.2020.9.6.1119-1125

\section{ARTICLE INFO}

Received 15. 10. 2019

Revised 4. 2. 2020

Accepted 4. 2. 2020

Published 1. 6. 2020

Regular article

OPEN $\partial_{\text {ACCESS }}$

\begin{abstract}
Noni fruit is hereditary used as herbal medicine of various diseases that can arise due to exposure of 7,12-dimethylbenz $[a]$ anthracene and cigarette smoke (DMBA-CS). This research aimed to assess the noni fruit extract (NFE) potential to maintaining the immune system from DMBA-CS exposure. The study with a completely random design was using male BALB/c mice (7-8 weeks old). NFE prepared with aqueous solvent and administered for five weeks (5x/week) with a dose of 30, 90, or $810 \mathrm{mg} / \mathrm{kg}$ of body weight (BW) per oral. After five weeks, NFE administration stopped, and mice were exposed with DMBA (20 mg/kg BW per oral) and CS for five minutes in five weeks (2x/week for each). This study also used a healthy group and a group that exposed to DMBA-CS without NFE administration. During the ten weeks of treatment, the body weight was measured. After the whole treatment, liver, kidney, lung, and spleen were isolated and weighed. Splenocyte cells were isolated for Flowcytometry. Data was analyzed in parametric by using OneWay ANOVA and post-hoc Tukey-HSD ( $p$-value $<0.05)$. The results showed the NFE helped the mice to maintain the weight when exposed to DMBA-CS. NFE was prevented the weight loss of the liver but not for spleen, whereas in the kidney and lung did not occur significant weight change in all groups. NFE at certain dosages modulated the expression of TNF- $\alpha$, IFN- $\gamma$, IL- 6 , and IL-1b. This study indicated that NFE potentially maintains the immune system homeostasis from DMBA-CS exposure.
\end{abstract}

Keywords: body weight, DMBA, cigarette smoke, immune system, noni fruit, organ weight

\section{INTRODUCTION}

Indonesia, as one of the country with a high diversity of flora, becomes one of the medicinal herb sources, namely noni plant (Morinda citrifolia L.), which has been established by the National Agency for Drug and Food Control of Republic of Indonesia (NADFC) as one of the main medicinal herbs that continue to be studied until clinically tested. The efficacy of the noni plant also has been proved hereditary by the community to cure various diseases such as hypertension, cancer, fever, cough, indigestion, depression, menstrual disorder, and drug dependence (Ali et al., 2016; Nuryunarsih, 2016; Sholikhah, 2016). However, few people understand that the noni plant, especially the fruit, can improve the body's immune system so that the noni fruit only used as a medicinal herb when the body is infected. Moreover, a study showed that the noni fruit could stimulate the activity of immunocompetent cells to kill cancer cells (Abou Assi $\boldsymbol{e t}$ al., 2017). Besides, described by Nelson \& Elevitch (2006), noni fruit contains a variety of compounds such as polysaccharides that serve as an immunomodulator and scopoletin which act as an anti-inflammatory compound. This becomes an indication that the noni fruit may potentially increase the body's immunity in healthy conditions so that the body becomes less susceptible to disease, moreover it is supported by the statement of $\mathbf{L i}$ et al. (2007) that the current environment contains many contaminants, pollutants and toxic compounds that cause a variety of diseases.

Two types of pollutants that are considered quite harmful to health are polycyclic aromatic hydrocarbons (PAHs) and free radicals. PAH, such as 7.12Dimetylbenz[a]anthracene (DMBA), is even referred to as a priority pollutant in the environment because it caused the most harmful impacts, can be found with high concentrations in the environment and humans are easily exposed to that compound (Rubailo \& Oberenko, 2008). While free radicals such as Reactive Oxygen Species (ROS) are also found in abundant quantities and are obtained from a diverse source, either endogenous (from mitochondrial activity, peroxysomes, and cell metabolism) or exogenous (from cigarette smoke, alcohol, pesticides, radiation) that can negatively affect the body's in an excessive amount (Phaniendra et al., 2015). In addition, the process of DMBA metabolism also produces intermediate compounds such as free radicals that increasingly exacerbate the human health condition by disrupting the immune system, including activities of immunocompetent cells (Li et al., 2007). Besides, DMBA and other types of PAH can trigger thymus atrophy; Pre-B cell apoptosis in bone marrow (candidate of B lymphocytes); inhibition of development and activity of $\mathrm{T}$ cells, B cells and myeloid cells, apoptosis of cells in lymphoid tissues such as spleen, lymph nodes, and Peyer's Patches; disruption of cytokine production; and inhibition of cellular and humoral immune systems including macrophage and Natural Killer cells (NK) as well as disturbances in the production of various types of proteins and cytokines such as interferon-gamma (IFN- $\gamma$ ), tumor necrosis factor-alpha (TNF- $\alpha$ ) and interleukin-6 (IL-6). While ROS is known to have a role in the regulation of immune system that mediated by $T$ cell lymphocytes, but if there is an error in the regulation, then it can trigger the formation of various diseases even autoimmune diseases (Burchiel \& Luster, 2001; Ahsan et al., 2003; Yarosz \& Chang, 2018).

In relation to the immunological effects of DMBA and ROS, which are quite harmful to human health, it is crucial to take a preventive effort so that the body does not become vulnerable to disease attacks. This preventive effort is possible to do by utilizing noni fruit extract because it can potentially increase immunity and act as an immunomodulatory agent. But there was no scientific evidence that showed the possibility of noni fruit extract as a protecting agent of the immune system dysregulation caused by DMBA exposure and ROS from cigarette smoke. Therefore this study aimed to assess the potential of the noni fruit extract for maintaining the homeostasis of the immune system from the negative effect of DMBA and cigarette smoke exposure that is known to have an abundant content of PAH and ROS.

\section{MATERIAL AND METHODS}

\section{Animal}

The Committee Ethics of Brawijaya University has approved this research with No. 1175-KEP-UB. The study was conducted in vivo in Animal Room and Laboratory of Physiology, Animal Structure, and Development, Department of Biology, Faculty of Natural Sciences, Brawijaya University, Indonesia, by using 
mice as the animal model (Mus musculus). Twenty male BALB/c mice (seven/eight-week-olds) are divided into five groups. The group of animals including healthy control $(\mathrm{N})$, one group that exposed by DMBA and cigarette smoke for five weeks without NFE administration (DMBA-CS), a group that administered with NFE $30 \mathrm{mg} / \mathrm{kg}$ body weight per oral for five weeks then exposed with DMBA and cigarette smoke for the next five weeks (D1-DMBACS), group D2-DMBA-CS (NFE $90 \mathrm{mg} / \mathrm{kg}$ BW per oral), and group D3-DMBACS (NFE $810 \mathrm{mg} / \mathrm{kg}$ BW per oral). Each mouse was treated in a $25 \times 20 \times 9 \mathrm{~cm}$ box, fed and drink regularly, kept clean, and the bodyweight was measured every day.

\section{Extraction of noni fruit}

The local noni fruit was extracted using an aqueous solvent. The ripe fruits which freshly picked were washed using water and were dried. The fruits were shredded and submerged with distilled water $\left(80^{\circ} \mathrm{C}\right)$ in a ratio of $1: 5(\mathrm{~g} / \mathrm{mL})$. The sample was incubated at $37^{\circ} \mathrm{C}$ for 24 hours. The sample was filtered, and the obtained solution was transferred to the glass bottle and then stored in the freezer until the solution getting frozen. After that, the sample was inserted into the engine ALPHA 1-2 LDplus Freeze Dryer (Martin Christ Gefriertrocknungsanlagen $\mathrm{GmbH}$, Germany) to get the noni fruit extract (NFE) (McKoy et al., 2002 with modifications)

\section{NFE administration}

NFE was orally administered per day for each mouse according to the dose of treatment and carried out for five weeks (five times/week). NFE was dissolved in distilled water with a concentration according to the prescribed dose $(30 \mathrm{mg} / \mathrm{kg}$ $\mathrm{BW}, 90 \mathrm{mg} / \mathrm{kg} \mathrm{BW}$, or $810 \mathrm{mg} / \mathrm{kg} \mathrm{BW}$ per oral). The NFE selected dose was determined from the effective dose/therapeutic dose of noni fruit in mice that have been measured by previous researchers (Chearskul et al., 2004; West et al., 2006; Palu et al., 2008, with modifications).

\section{Exposure of DMBA and cigarette smoke}

The exposure of DMBA (Tokyo Chemical Industry Co., Ltd., Tokyo, Japan) and cigarette smoke (Gudang Garam, Indonesia) (DMBA-CS) was conducted with a total time of five weeks after the mice have been administered with NFE. Mice were administered with DMBA that dissolved in corn oil (CV. Surya Agung, Surabaya, Indonesia) in a concentration of $20 \mathrm{mg} / \mathrm{kg} \mathrm{BW}$ per oral per day for five weeks (twice/week). Mice were exposed with cigarette smoke (the whole-body exposure) on the same week (twice/week) for five minutes for each exposure in a $4 \times 20 \times 20 \mathrm{~cm}$ chamber (one mouse in a chamber). The exposure of cigarette smoke was done on the day when the mice were not administered with DMBA (Wan et al., 2010; Juhász et al., 2013; Sahoo et al., 2014; with modifications).

\section{Organ isolation}

All mice were sacrificed with the dislocation technique of the neck on the tenth week after all the treatments were completed (NFE administration and DMBA CS exposure). The spleen, liver, kidney, and lung organs were isolated, and the weights were measured by using a digital scale (GX-600 milligram balance, A\&D Weighing, USA). The spleen was washed with a sterile PBS (Phosphate Buffer Saline), placed in a Petri dish containing a sterile PBS and then homogenized. The cell suspension was inserted into the $15 \mathrm{~mL}$ polypropylene tube and added with the PBS until the volume was equivalent to another cel suspension of the spleen. The cell suspension was centrifuged for $2500 \mathrm{rpm}$ (five minutes, $10^{\circ} \mathrm{C}$ ). After centrifugation, the supernatant was discarded, and the pellet was resuspended with $1 \mathrm{~mL}$ of PBS (Rifa'i \& Widodo, 2014 with modifications).

\section{Flow cytometry (FCM)}

Fifty microliters of the resuspended splenocytes were added with $50 \mu \mathrm{L}$ of extracellular antibodies then incubated in the icebox for 20 minutes. The splenocytes were added with $50 \mu \mathrm{L}$ of fixative solution (BD Cytofix/Cytoperm, BD Biosciences, San Jose, CA) and re-incubated. The splenocytes then were added with $300 \mu \mathrm{L}$ of washperm solution (BD Perm/Wash ${ }^{\mathrm{TM}}$, BD Biosciences, San Jose, CA), then centrifuged at a speed of $2500 \mathrm{rpm}$ (five minutes, $10^{\circ} \mathrm{C}$ ). After the centrifugation, the supernatant removed and the pellet was mixed with $50 \mu \mathrm{L}$ of intracellular antibodies then incubated for 20 minutes. The cell suspension was mixed with $300 \mu \mathrm{L}$ PBS and transferred to FCM cuvettes for subsequent readings of samples on FCM BD FACSCalibur ${ }^{\mathrm{TM}}$ machine (BD Biosciences, San Jose, CA), then results were analyzed by using BD CellQuest Pro $^{\mathrm{TM}}$ software (BD Biosciences, San Jose, CA) (Dwijayanti et al., 2015). The combination of antibodies and fluorochromes that used in this study were the FITC-conjugated rat anti-mouse CD4, PE-conjugated rat anti-mouse TNF- $\alpha$, $\mathrm{PE} / \mathrm{Cy} 5$-conjugated rat anti-mouse IFN- $\gamma$; FITC-conjugated rat anti-mouse CD8, PE-conjugated rat anti-mouse TNF- $\alpha, \mathrm{PE} / \mathrm{Cy} 5$-conjugated rat anti-mouse IFN- $\gamma$; FITC-conjugated rat anti-mouse CD4, PE-conjugated rat anti-mouse B220, $\mathrm{PE} / \mathrm{Cy} 5$-conjugated rat anti-mouse IL1- $\beta$; and FITC-conjugated rat anti-mouse CD11b, PE-conjugated rat anti-mouse IFN- $\gamma, \mathrm{PE} / \mathrm{Cy} 5$-conjugated rat anti-mouse IL-6 (BioLegend, San Diego).

\section{Data analysis}

The results of the FCM data analysis were tabulated and processed using the Microsoft Excel program for Windows 10. From the tabulation and processing data, the relative number of cells of each parameter was analyzed statistically on SPSS 16.0 for Windows (IBM Corporation, US) software by using the One-Way ANOVA parametric analysis and continued with Tukey HSD posthoc test with significance of $95 \%$ ( $p$-value $<0.05)$ (Gamst et al., 2008).

\section{RESULTS}

The changing of mice body weight in all treatment groups was so dynamic from the beginning to the end of the treatment. Based on Figure 1a, the NFE administration for five weeks caused the changing in body weight with a higher tendency that occurred in the mice group that administered with $30 \mathrm{mg} / \mathrm{kg} \mathrm{BW}$ per oral of NFE. The body weight can be maintained even administration of NFE at all three doses can increase body weight when mice were exposed to DMBA$\mathrm{CS}$, despite the fact that the decline occurred in the last days of DMBA-CS exposure (Figure 1b). Moreover, based on Figure 1b, it can be showed that the D3-DMBA-CS group has the highest tendency of body weight increase during DMBA-CS exposure. It indicated that NFE potentially maintains mice body weight when exposed to DMBA-AR depending on the dosage used.

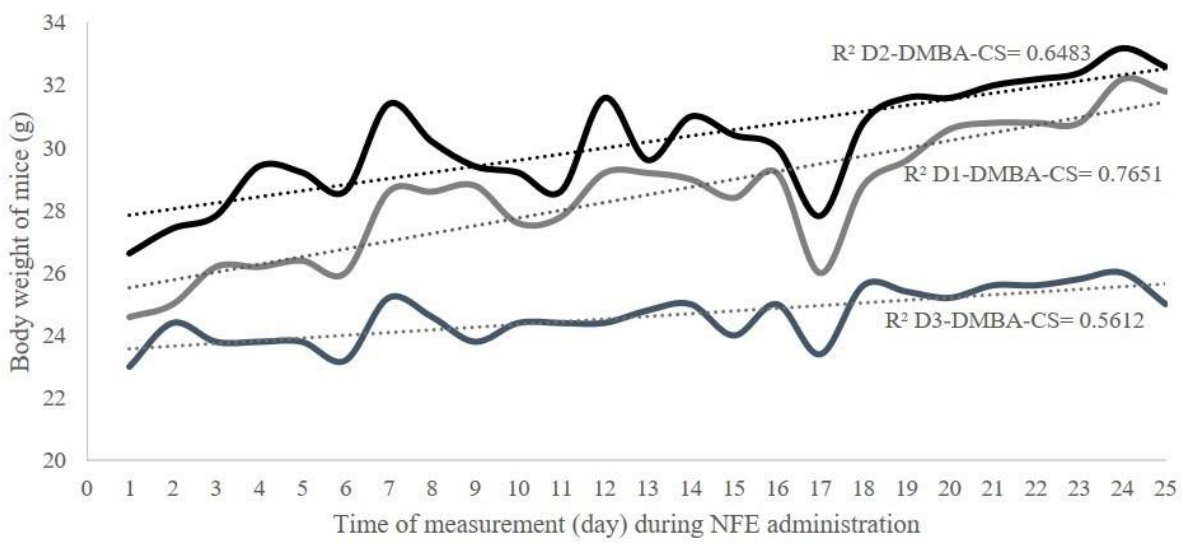

a.

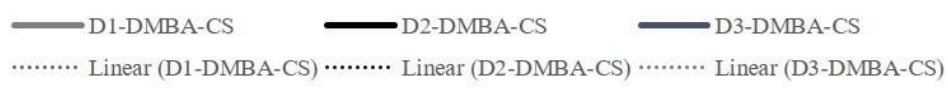




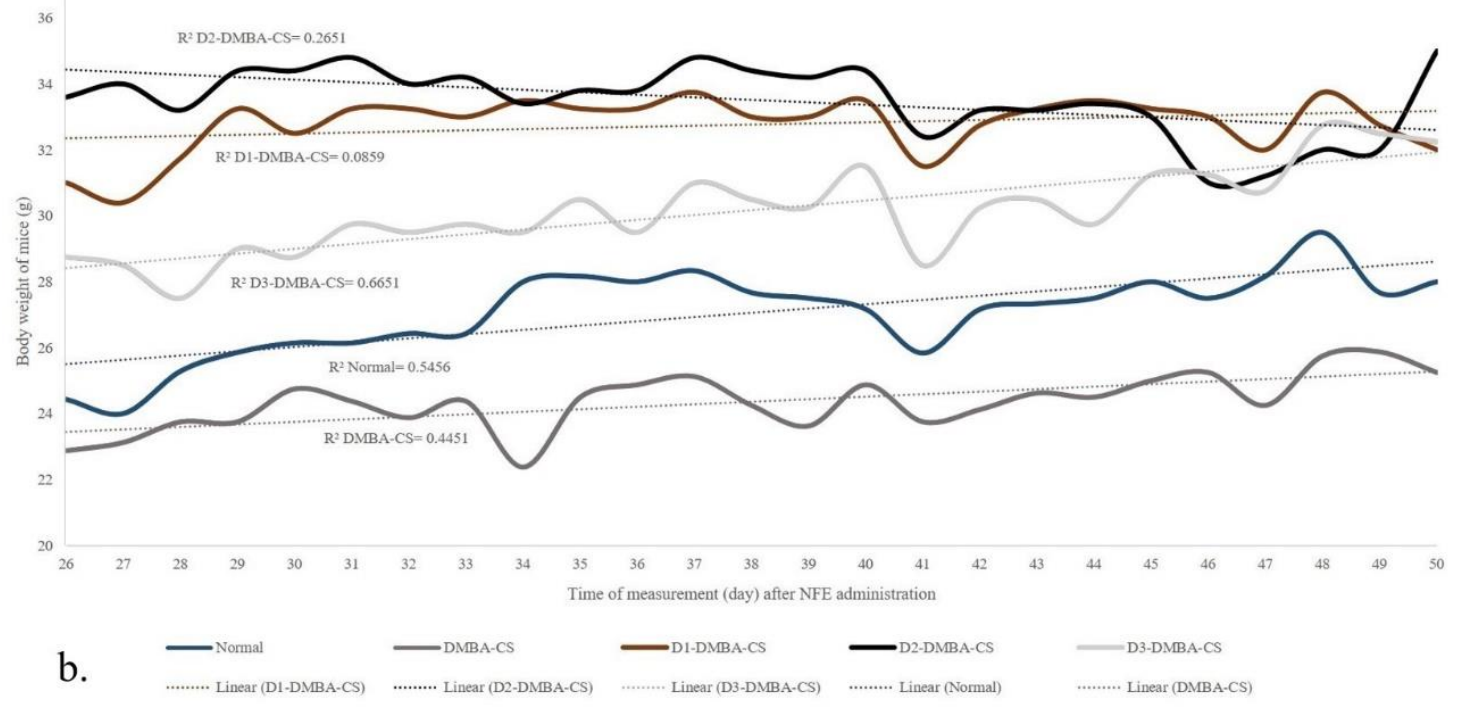

Figure 1 Body weight of mice (g) (a) during NFE administration and (b) after NFE administration during DMBA-CS exposure. Normal= healthy mice; DMBA-CS= mice exposed to DMBA-CS; D1-D3 DMBA-CS= mice exposed to DMBA-CS, which previously administered with NFE for 30, 90, or 810 mg/kg BW. Data are the mean of four mice for each group.

NFE influenced not only the mice's body weight but also the weight of the liver when mice exposed to DMBA-CS. Based on Figure 2, the kidney and lung did not undergo a significant weight change in all treatment groups, while the spleens in all groups exposed to DMBA-CS have a lower weight than the healthy group. It suggests that the NFE administration has not been able to restore or prevent the weight loss of the spleen caused by DMBA-CS exposure. The fact showed that the liver weight of mice exposed to DMBA-CS suffered significant weight reduction ( $p$-value $<0.05)$ when compared to normal mice, but the administration of NFE for five weeks on the three doses potentially prevented the declining of liver weight. This indicated that NFE might work to protect, restore, or prevent the weight loss of the liver when mice exposed to DMBA-CS.

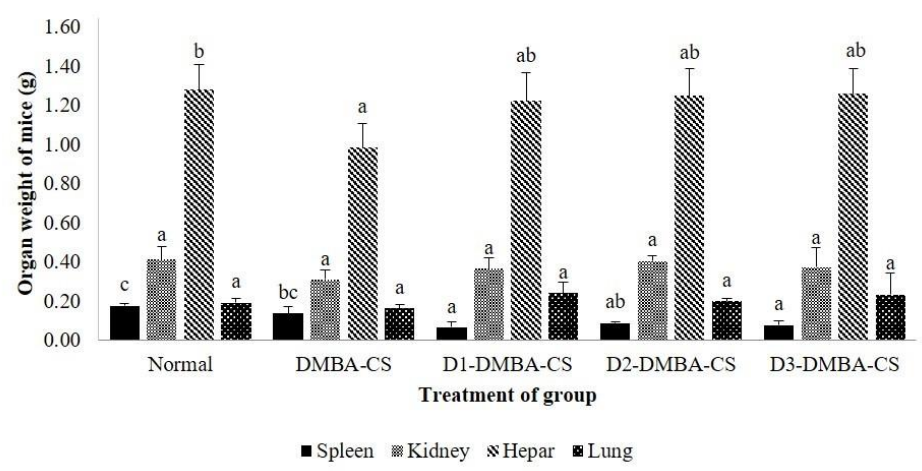

Figure 2 Organ weight of mice (g) after oral administration of NFE and DMBA CS exposure. Normal= healthy mice; DMBA-CS $=$ mice exposed to DMBA-CS; D1-D3 DMBA-CS= mice exposed to DMBA-CS, which previously administered with NFE for 30,90 , or $810 \mathrm{mg} / \mathrm{kg}$ BW. Data are mean \pm SD of four mice for each group. Different notations mean significantly different results ( $p$-value $<$ $0.05)$.

Moreover, NFE also demonstrated its potential for protection by modulating mice's immune system, especially in preventing the changing of cytokine expression caused by DMBA-CS. As shown in Figure 3, the relative number of $\mathrm{CD}^{+} \mathrm{TNF}^{+} \mathrm{T}$ cells significantly reduced in DMBA-CS group when compared to the healthy group, but this significant declining could be prevented in D2 DMBA-CS group that previously had been administered with $90 \mathrm{mg} / \mathrm{kg} \mathrm{BW}$ of NFE. The reduction of the relative number of $\mathrm{CD} 4^{+} \mathrm{TNF}^{+} \mathrm{T}$ cells was inversely proportional to the relative number of $\mathrm{CD}^{+}{ }^{+} \mathrm{IFN} \gamma^{+} \mathrm{T}$ cells which increased in DMBA-CS. However, thus increasing can be prevented in D3-DMBA-CS group. The TNF- $\alpha$ and IFN- $\gamma$ cytokine expressions on CD4 T cells differed if compared with $\mathrm{CD} 8 \mathrm{~T}$ cells. Based on Figure 4, either the relative number of $\mathrm{CD} 8^{+} \mathrm{TNF}^{+} \mathrm{T}$ cells or CD8+IFN $\gamma+\mathrm{T}$ cells are increased in the DMBA-CS group when compared to normal group but are decreased in all mice which previously given NFE orally. For the relative number of B220 $\mathrm{IL} 1 \mathrm{~b}^{+} \mathrm{B}$ cells (Figure 5), an increase occurred in the entire groups of mice exposed to DMBA-CS. In this case, NFE has not been able to prevent the increasing number of $\mathrm{B} 220^{+} \mathrm{IL} 1 \mathrm{~b}^{+}$cells that occurred when mice suffered DMBA-AR exposure. Similarly, the relative number of $\mathrm{CD} 11 \mathrm{~b}^{+} \mathrm{IL} 6^{+}$macrophage cells (Figure 5) also increased in the entire groups exposed to DMBA-CS, but the NFE in dose 30 and $810 \mathrm{mg} / \mathrm{kg}$ BW per oral significantly inhibit those increasing toward normal condition.

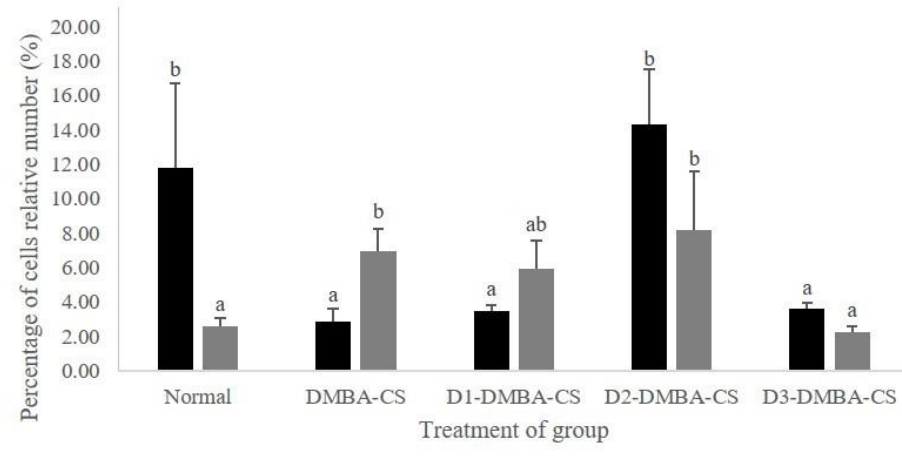

- Relative number of CD4+TNFa+ cells (\%) nelative number of CD4+IFNg+ cells (\%)

Figure 3 TNF- $\alpha$ and IFN- $\gamma$ expression on CD4 T cells after oral administration of NFE and DMBA-CS exposure. Normal $=$ healthy mice; DMBA-CS $=$ mice exposed to DMBA-CS; D1-D3 DMBA-CS= mice exposed to DMBA-CS, which previously administered with NFE for 30,90 , or $810 \mathrm{mg} / \mathrm{kg} \mathrm{BW}$. Data are mean \pm SD of four mice for each group. Different notations mean significantly different results $(p$-value $<0.05)$.

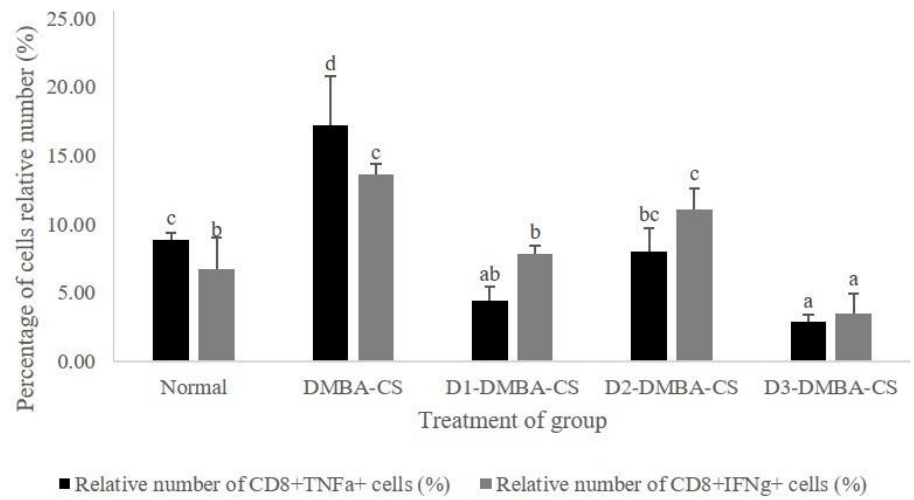

Figure 4 TNF- $\alpha$ and IFN- $\gamma$ expression on CD8 T cells after oral administration of NFE and DMBA-CS exposure. Normal $=$ healthy mice; DMBA-CS $=$ mice exposed to DMBA-CS; D1-D3 DMBA-CS= mice exposed to DMBA-CS, which previously administered with NFE for 30,90 , or $810 \mathrm{mg} / \mathrm{kg} \mathrm{BW}$. Data are mean \pm SD of four mice for each group. Different notations mean significantly different results $(p$-value $<0.05)$. 


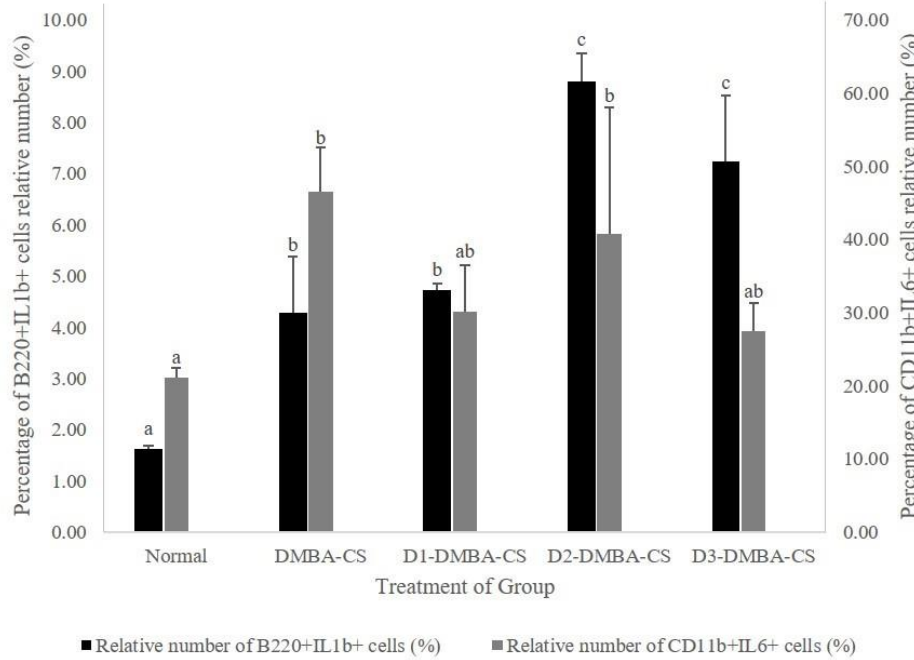

Figure $5 \mathrm{IL}-1 \mathrm{~b}$ expression on B cells and IL-6 expression on macrophage cells after oral administration of NFE and DMBA-CS exposure. Normal= healthy mice; DMBA-CS= mice exposed to DMBA-CS; D1-D3 DMBA-CS= mice exposed to DMBA-CS, which previously administered with NFE for 30, 90, or $810 \mathrm{mg} / \mathrm{kg} \mathrm{BW}$. Data are mean \pm SD of four mice for each group. Different notations mean significantly different results $(p$-value $<0.05)$.

\section{DISCUSSION}

In this study, we used an aqueous solvent to extract the noni fruit. We preferred to choose aqueous solvent rather than other organic solvents such as methanol or ethanol because we referred to the reality in a community which usually use water to get noni fruit extract or juice (Nelson \& Elevitch, 2006). Moreover, the result of the LC-MS test (data not shown), NFE with aqueous solvent contained some compounds that serve antioxidant activity, including quercetin and rutin. By using aqueous solvent, we expect that our result can be used as one of the scientific data to support the utilization of plants as alternative medicine or as an alternative to prevent the occurrence of illness caused by pollutants such as DMBA and cigarette smoke.

NFE potentially maintained the mice body weight when exposed to DMBACS

Bodyweight is one of the essential parameters that show physical health as well as physiological and metabolic parameters that are measured to determine how a treatment gives effect to the mice (Hutchinson et al., 2005; Fawcett, 2012). In this study, mice weight during five weeks of NFE administration tended to increase with the highest rate occurred in mice given $30 \mathrm{mg} / \mathrm{kg} \mathrm{BW}$ of NFE. This fact provided information that NFE was able to help increase or at least maintain the mice's weight in healthy conditions, and this condition occurred depending on the dose applied. As the results of the research conducted by De Sousa et al. (2017), the oral administration of noni fruit juice for nine days does not give a significant impact on body weight. This result was in correlation with no deleterious impact on intestinal structure after noni fruit juice administration for nine days so that there was no perturbation in the compound or nutrition absorption and thus did not impact on weight loss. According to De Sousa et al., a short period of noni fruit consumption has no adverse effect on body weight in healthy condition. So that, our study completed the results by De Sousa $\boldsymbol{e t}$ al. which the oral administration of NFE conducted in a longer period also does not affect body weight in healthy conditions, moreover tended to increase or maintain the mice's weight.

Furthermore, oral administration of NFE for five weeks also helped maintain the weight when mice were exposed to DMBA orally and cigarette smoke in the next five weeks, although the weight was briefly decreased in the last days of exposure. This evidence not only occurred in DMBA-CS exposure, but also in picric chloride exposure, in which mice weight do not undergo adequate changes (Murata et al., 2014). However, the consumption of noni fruit juice decreases mice's weight in the case of obesity (Inada et al., 2017) and Ehrlich carcinoma ascites (EAC) (Ali et al., 2018). All of those indicate that the noni fruit extract or juice causes a different response for mice weight depending on the condition of the body.

The results of this study differed from others (Thamizharasi et al., 2019), in which exposure to DMBA led to significant weight loss in mice for 25 weeks. Similarly, the exposure of cigarette smoke significantly causes weight loss, even only in two days (Chen et al., 2005). The different results may be due to differences in DMBA exposure intensity, time of measurement, also the strain and the age of mice.
The fluctuation of body weight monitored in this study during ten weeks of treatment may be due to some factors. According to Institute of Medicine (US) Subcommittee on Military Weight Management (2004), there are many factors influenced management of body weight, including developmental determinants (prenatal factors, adiposity, adolescence, adulthood), genetic determinants (animal model of genetic obesity, familial aggregation), age, race or ethnicity, physical activity, food (intake, composition, portion size, meal patterns, eating habits), physiological factors (resting metabolic rate, thermic effect, energy expended), environmental factors (smoking, alcohol, pharmacological agents), and social factors (family and ethnicity, status of socioeconomic). We argue that the dynamic changing of body weight of mice in this study was occurred because of different intake of food, differences in energy metabolism and metabolic activity, differences of physical activity, and environmental factors including NFE administration and exposure of DMBA also cigarette smoke. In this study, we can't control how much the intake of food by each mouse although we gave the standard food in the same amount. During the monitoring of body weight, we observed that each mouse group has different physical activity. Administration of NFE and DMBA-CS contribute to body weight changing because both of NFE and DMBA-CS act as external environments with different roles. As mentioned by Audrain-McGovern \& Benowitz (2011), cigarette smoke contains nicotine which affects the metabolic rate in the body so that it influences the changing of body weight. We assume that NFE become pharmacological agents that may take a role in helping the mice to maintain the body weight, because as the previous explanation by Murata et al. (2014) and Inada et al. (2017), noni fruit causes a changing of mice bodyweight to depend on the condition of the body, including in health condition, obesity, and diseases.

\section{NFE potentially prevent toxic effect of DMBA-CS toward liver weight}

The organ weight of the animal is one of the important indicators to be measured and to be studied in order to test toxicological and to learn the potential benefits of herbs, compounds or certain drugs also industrial products (Michael et al., 2007; Sellers et al., 2007; Mensah et al., 2019). According to Michael et al. (2007), there are some organs that important to be weighed in a scientific study using animal models, including the liver as its vital function in metabolism, kidney, thymus, spleen, heart, brain, lung, and reproductive organ. So that in this study, we measured and compared some organ weight as one of the clinical signs to evaluate the potential of NFE to prevent the changing of organs weight caused by DMBA-CS as a pollutant source. In our study, DMBA-CS exposure has no effect on the kidney and lung weight, as well as those that previously had been administered with NFE. We assume that the protection system such mucosa in the respiratory tract minimized the entering of a pollutant from CS toward alveoli and DMBA from the gastrointestinal tract has been metabolized or distributed to other organs rather than the kidney. However, the absence of significant organ weight differences when mice exposed to DMBA-CS did not give a conclusion that the kidney and lung are healthy enough. Based on the study by Ozturk et al. (2006) and Cooper (2006), DMBA exposure (20 mg/kg BW of mice) and cigarette smoke can interfere with the renal function that leads to nephropathy, microalbuminuria, proteinuria of the proximal and distal tubule. On the other side, it is known that the consumption of noni fruit juice in a short period in healthy condition does not affect the function of kidneys (De Sousa et al., 2017). Whereas the International Agency for Research on Cancer (2004) states that exposure to DMBA and cigarette smoke can trigger the formation of tumor cells in the lung with a dose and a certain period.

In opposite with the weight of the kidney and lung, the spleen from all groups exposed to DMBA-CS had a lower weight than the normal group. These results indicated that DMBA-CS exposure might cause weight loss of the spleen and it couldn't be prevented or inhibited by oral administration of NFE. We assume that it could happen because the dosage of DMBA or quantity of cigarette smoke was too high or the doses of NFE were not sufficient to prevent the weight loss of spleen caused by DMBA-CS exposure so that the higher dose of NFE might be needed. However, in this study, we could not estimate the amount of cigarette smoke inhaled by the mice. This finding corresponded to the study by Gao et al. (2007) and Diniz et al. (2013) which the oral administration of DMBA (cumulative doses of 50 and $150 \mathrm{mg} / \mathrm{kg} \mathrm{BW}$ for 5 days) and exposure to cigarette smoke ( 3 times exposure/day for 21 days) cause the weight loss of spleen and the number of lymphocytes isolated from the spleen. But in this study, the potential of NFE in preventing the weight loss of spleen due to the exposure of DMBA-CS couldn't be shown. It was possible to occur due to a high level of DMBA-CS toxicity for spleen or lack of dose of NFE used. Nevertheless, Hong et al. (2019) indicate that the noni fruit extract with water solvent which mix with a microbial pectin enzyme modulates the splenocytes populations by increasing the number of NK cells which expressed IFN- $\gamma$ cytokine, although the oral administration of the extract for four weeks (once a week) has no effect on the change in the weight of the spleen $(100-400 \mu \mathrm{g} / \mathrm{mL})$.

Although the NFE couldn't prevent the weight loss of the spleen, it was proven that NFE is potentially prevented the weight loss of liver in mice exposed to DMBA-CS. In line with the study by Wang et al. (2008), noni fruit juice provides a protective effect on the liver and causes no damage to the liver. 
Research conducted by Wang $\boldsymbol{e t}$ al. (2008) in rats gives the implication that noni fruit is beneficial to prevent the incidence of toxicity in the liver, including hepatotoxic lesions that occur due to exposure of carbon tetrachloride toxin (CCL4) orally. In our study, the source of toxins derived from DMBA-CS, which entered the body in an oral or inhalation way was significantly caused a weight loss of liver when compared to healthy mice. This fact indirectly suggests that DMBA-CS may trigger damage to the liver, but it can be prevented by consuming the extracts or juices of noni fruit. Our finding also supported the results of previous studies that examined the potential of noni fruit in protecting liver as the main organ of metabolism due to various disorders that may occur including decrease enzymatic activity (Wang $\boldsymbol{e t}$ al., 2008) and the damage caused by alcohol exposure (Chang et al., 2013), although consumption of the noni fruit may trigger liver disruption in certain cases (Stadlbauer et al., 2005; Stadlbauer et al., 2008). However, the potential of noni fruit as a protective agent for the liver is possible because the fruit has quercetin and rutin compounds that have antioxidant activity, can regulate lipid homeostasis, metabolism the alcohol, and modulate the immune system as an anti-inflammatory agent (Chang et al., 2013). The previous study by West et al. (2009a) and West $\boldsymbol{e t}$ al. (2009b) showed that noni fruit juice does not cause toxicity and the deleterious effect for liver. Another study by Shalan $\boldsymbol{e t}$ al. (2017) showed that aqueous extract of noni fruit could induce liver and kidney damage if the extract contains carcinogenic agents such as anthraquinone.

\section{NFE potentially prevent toxic effect of DMBA-CS by modulating mice immune system}

In this study, the specific antibodies were used in FCM to identify the cells target and the cytokines that expressed by those cells, including TNF- $\alpha$ and IFN- $\gamma$ in CD4 T cells and CD8 T cells, IL-1b in B cells, and IL-6 in macrophage cells. CD4 $\mathrm{T}$ cells, CD8 $\mathrm{T}$ cells, and B cells are the main cells in the adaptive immune system, whereas macrophage is the important cells also act as one of Antigen Presenting Cells (APCs) in the innate immune system. Despite, the cytokines that studied in this research, TNF- $\alpha$, IFN- $\gamma$, IL- $1 b$, and IL- 6 , are some of cytokines which important for regulation of inflammation mechanism and used by immune cells to communicate with other cells to regulate the immune system (Yatim \& Lakkis, 2010; Cauvi et al., 2017). Besides, each of those cytokines has correlation with others cytokine such as TNF- $\alpha$ can stimulate IL-1 and IL-6 biosynthesis (Neta et al., 1992); TNF- $\alpha$, IL-1b, and IL-6 can act a redundant activity to stimulate the growth and differentiation of lymphocytes (Akira $\boldsymbol{e t} \boldsymbol{a l}$., 1990); IFN- $\gamma$ can interact with IL-6 also in correlation with TNF- $\alpha$ and IL-1b activity to regulate inflammatory response (Cauvi $\boldsymbol{e t}$ al., 2017). That activity of cytokines may be interrupted by exposure of pollutants such DMBA and cigarette smoke and there was a possibility that interruption can be prevented by the use of plant extract.

Overall, this study showed that NFE was able to modulate the immune system when mice exposed to DMBA-CS depending on the dose used. Such modulation occurred because either DMBA-CS or NFE provided varying effects on each of the immunocompetence cell activities studied. For CD4 T cells, DMBA-CS caused a decrease in TNF- $\alpha$ expression but enhanced the expression of IFN- $\gamma$. In general, both cytokines are important especially for the mechanism of inflammation. But in this study, the expression of TNF- $\alpha$ was decreased after DMBA-CS exposure. The different expressions of TNF- $\alpha$ and IFN- $\gamma$ might cause the dysregulation of immune system. The differences of cytokine expression might be caused by the various acts of DMBA and ROS from cigarette smoke inside the cell, including inhibition or activation of Nuclear Factor-Kappa B (NF$\mathrm{\kappa B})$ as one of a transcription factor, depending on the mechanism occurred (Morgan \& Liu, 2011; Corsini \& van Loveren, 2015). Based on those activities of DMBA and cigarette smoke, we can assume that either DMBA or cigarette smoke not only caused the increase of inflammatory response but also dysregulate the activity of immune cells by disrupting the normal mechanism of inflammatory cytokine production. The decline and increase of each expression can be prevented by NFE independent doses. We argue that the decreasing of TNF- $\alpha$ expression in CD4 T cells caused by DMBA-CS exposure could be preventing in D2-DMBA-CS group as an effort to turned back the balance condition of TNF- $\alpha$ expression, as compared with the normal group. For CD8 T cells, all doses of NFE worked quite effectively in suppressing the expression of TNF- $\alpha$ and IFN- $\gamma$. For macrophage cells (CD11b cells), the lowest and highest dose of NFE has the potential to decrease the expression of IL-6 that tends to increase due to DMBA-CS exposure. But the potential of NFE at all three doses has not been seen in preventing the increase of IL-1b expression on B cells. We can't assume that NFE increase the inflammatory response just because of the increasing of IL-1b expression in B cells. We argue that the incapacity of NFE to prevent the increasing of IL-1b occurred because the NFE doses that used in this study were not enough or couldn't work optimally to protect B cells from the defect in cytokine production pathway which caused by DMBA-CS. These results indicated that NFE in dependent-dose is potential to help in modulating the immune system by preventing the changing of cytokine expression which occurred after the exposure of DMBA-CS.
According to this study, the immunocompetence cells isolated from the spleen have a varied expression of cytokines, including TNF- $\alpha$, IFN- $\gamma$, IL- 6 , and IL- $1 \mathrm{~b}$, which have played an important role in inflammatory pathways. The increase and decrease expression of those cytokines demonstrated the potential of NFE in modulating the immune system so that the components of the inflammatory pathways continue to work to reach a balance condition when the mice were exposed to toxins derived from DMBA and cigarette smoke. As the previous explanation, either DMBA or cigarette smoke may cause alteration or damage to the spleen (Gao et al., 2007; Diniz et al., 2013). As a secondary lymphoid organ, the activity of immunocompetence cells will be interrupted in case of any alteration in the spleen. It was supported by the explanation of Lee $\boldsymbol{e t}$ al. (2012) that cigarette smoke can disturb the inflammatory pathways and suppress the activity of immunocompetence cells. The ROS contained in cigarette smoke may affect the activation of cytokine and IFN- $\gamma$ coding gene in T cells through modulation of the activity of gene transcription factors such as NF- $\mathrm{KB}$ and Activator Protein-1 (AP-1). It may occur in other cytokine coding genes, including IL- 6 in macrophage and IL-1b cells in B cells. Not only cigarette smoke, but also DMBA and other PAH types can give an adverse effect to immune activity (immunosuppression), either humoral or cellular immunity including the decrease of recovery ability in lymphoid cells, apoptosis of pre-B cells, decreased of B cell capacity in producing antibodies, suppression of T cell and B cell proliferation, and inhibit the activity of macrophage cells (Burchiel \& Luster, 2001).

The effects of immunosuppression from DMBA and cigarette smoke can be prevented or at least can be minimized by using oral administration of NFE. As explained by Palu et al. (2008), noni fruit juice may suppress interleukin-4 (IL-4) cytokine production, increase the production of IFN $-\gamma$, and activate the CB2 receptor (type 2 cannabinoid receptors) needed in development, migration, proliferation and effector activity of immunocompetence cells. Supported with a study by Nayak \& Mengi (2010), the aqueous and hydroalcoholic extract of noni fruit can trigger the immune response by $\mathrm{T}$ cells and $\mathrm{B}$ cells. According to Murata et al. (2014), noni fruit extract has a compound, namely deacetylasperuloside acid, that can increase the recovery of the cellular immune system, including activating the NK cell and preventing the suppression of IL-2 production that needed for the proliferation of immunocompetence cells. Besides, some compounds in noni fruit are known to have immunostimulatory activity and help the modulation of immune systems such as polysaccharides and alkaloids (Nayak \& Mengi, 2010). Besides, noni fruit contains quercetin that can inhibit the upregulation of NF-KB which caused by DMBA (Li et al., 2016).

In this study, we found that each immune cell and cytokines have their own function but overall, they take a role in inflammation mechanism. DMBA and cigarette smoke do not always promote inflammation response directly by immune cells. According to Burchiel \& Luster (2001), DMBA and another type of PAHs can attenuate the immune cells activity by disturb the growth, development, and effector activity of $\mathrm{T}$ cells, $\mathrm{B}$ cells, and macrophage by mechanism as explained before by (Morgan \& Liu, 2011; Corsini \& van Loveren, 2015). DMBA can be metabolized to DMBA-epoxide by some enzymes including Cytochrome $\mathrm{P} 450$ and microsomal epoxide hydrolase. DMBA-epoxide can induce DNA adduct and lead to apoptosis mechanism inside the cell (Gao et al., 2008). The apoptosis mechanism supposes to be one factor that causes the death of splenocytes and impact on the decrease of spleen weight. It had been mentioned by Yang $\boldsymbol{\&}$ Xu (2011) that cell death is one of the intracellular factors which influenced the cell number and organ size. In this study, we found that the weight loss of spleen did not always in line with the decreasing cytokine expression. The cells that expressed cytokine especially B cells increased in DMBA-CS group which previously administered with NFE but the spleen weight was decreased. According to Kapila \& Tuma (2018) and Shazia \& Panuganti (2019), the spleen compose of lymphatic tissue; blood tissue including venous sinuses; periarteriolar lymphoid sheath (PALS); reticulin and fibrils as the monocytes reservoir; and some types of cells including B cells; T cells; macrophages, white blood cells, also platelets. In this study, we can't predict what kind of cells that death after DMBA-CS exposure because there are many kinds of cells and tissues that compose the spleen.

On the other hand, we can't argue that NFE was toxic for splenocytes. There was no study before which proved the toxicity of noni fruit in the spleen. The toxicity test of noni fruit just seen in the liver, not for kidney or spleen, but that hepatotoxicity only occurred if the extract or juice of noni fruit contains anthraquinone (Stadlbauer et al., 2005; Shalan et al., 2017).

Overall according to our results, advanced research including the study of spleen histology after NFE administration and the study of another cytokine expression, moreover gene expression in immune cells and the activity of transcription factors that have responsibilities in gene expression are still needed to be observed to determine the precisely mechanism how NFE can modulate the immune system, whether in healthy or the condition of toxin exposure and diseases, especially in DMBA and cigarette smoke exposure. 


\section{CONCLUSION}

NFE with certain doses in the male BALB/c mice potentially maintain the immune system homeostasis from DMBA and cigarette smoke exposure. The use of NFE helps the maintaining of metabolism and assists the recovery process or prevention of liver weight loss in the case of exposure to toxic compounds from DMBA and cigarette smoke. Furthermore, the NFE has the potential of maintaining the immune system by protecting from the harmful effects of DMBA and cigarette smoke toward the function of the immune system, especially in cytokine-producing cells that play an important role in inflammatory processes. The NFE can prevent the dysregulation of TNF- $\alpha$ and IFN- $\gamma$ expression in CD4 T cells and CD8 T cells, also IL-6 expression in macrophage. Thus, the overall results of this research become scientific evidence to support the use of noni fruit in preventing the occurrence of diseases due to the exposure of toxins and as herbal medicines in the community. Further researches are still needed to know a clear mechanism of NFE potential to maintain the homeostasis of the immune system during the exposure of DMBA and cigarette smoke.

Acknowledgments: Authors thank Laboratory of Animal Physiology, Department of Biology, Faculty of Mathematics and Natural Sciences, Brawijaya University, Indonesia.

\section{REFERENCES}

Abou Assi, R., Darwis, Y., Abdulbaqi, I. M., Khan, A. A., Vuanghao, L., \& Laghari, M. H. (2017). Morinda citrifolia (Noni): A comprehensive review on its industrial uses, pharmacological activities, and clinical trials. Arabian Journal of Chemistry, 10(5), 691-707. http://dx.doi.org/10.1016/j.arabjc.2015.06.018 Ahsan, H., Ali, A., \& Ali, R. (2003). Oxygen free radicals and systemic autoimmunity. Clinical and Experimental Immunology, 131(3), 398-404. https://doi.org/10.1046/j.1365-2249.2003.02104.x

Akira, S., Hirano, T., Taga, T., \& Kishimoto, T. (1990). Biology of multifunctional cytokines: IL 6 and related molecules (IL 1 and TNF). FASEB Journal, 4(22), 2860-2867.

Ali, M., Kenganora, M., \& Manjula, S. N. (2016). Health benefits of Morinda citrifolia (Noni): A review. Pharmacognosy Journal, 8(4), 321-334. https://doi.org/10.5530/pj.2016.4.4

Ali, M., Mruthunjaya, K., Nandini, C., Nabeel, M., Anjali, R., \& Manjula, S. N. (2018). Evaluation of beneficial effects of Morinda citrifolia L. in presence of cisplatin on Erlich's ascites carcinoma bearing mice. International Journal of Pharmaceutical Sciences and Research, 9(1), 305-312. http://dx.doi.org/10.13040/IJPSR.0975-8232.9(1).305-12

Audrain-McGovern, J., \& Benowitz, N. L. (2011). Cigarette smoking, nicotine, and body weight. Clinical Pharmacology and Therapeutics, 90(1), 164-168. https://dx.doi.org/10.1038\%2Fclpt.2011.105

Burchiel, S. W., \& Luster, M. I. (2001). Signaling by environmental polycyclic aromatic hydrocarbons in human lymphocytes. Clinical Immunology, 98(1), 2-10. https://doi.org/10.1006/clim.2000.4934

Cauvi, D. M., Cauvi, G., Toomey, C. B., Jacquinet, E., \& Pollard, K. M. (2017) From the cover: Interplay between IFN- $\gamma$ and IL-6 impacts the inflammatory response and expression of interferon-regulated genes in environmental induced autoimmunity. Toxicological Sciences, 158(1), 227-239.

Chang, Y. Y., Lin, Y. L., Yang, D. J., Liu, C. W., Hsu, C. L., Tzang, B. S., \& Chen, Y. C. (2013). Hepatoprotection of noni juice against chronic alcohol consumption: Lipid homeostasis, antioxidation, alcohol clearance, and antiinflammation. Journal of Agricultural and Food Chemistry, 61(46), 1101611024. https://doi.org/10.1021/jf4038419

Chearskul, S., Kooptiwut, S., Chatchawalvanit, S., Onreabroi, S., Churintrapun, M., Saralamp, P., \& Soonthornchareonnon, N. (2004). Morinda citrifolia has very weak estrogenic activity in vivo. Thai Journal of Physiological Sciences, 17(1), 22-29.

Chen, H., Vlahos, R., Bozinovski, S., Jones, J., Anderson, G. P., \& Morris, M.J. (2005). Effect of short-term cigarette smoke exposure on body weight, appetite, and brain neuropeptide Y in mice. Neuropsychopharmacology, 30(4), 713-719. https://doi.org/10.1038/sj.npp.1300597

Cooper, R. G. (2006). Effect of tobacco smoking on renal function. Indian Journal of Medical Research, 124(3), 261-268

De Sousa, B. C., Miguel, C. B., Rodrigues, W. F., Machado, J. R., da Silva, M V., da Costa, T. A., Lazo-Chica, J. E., Degasperi, T. P., Sales-Campos, H., Bucek, E. U., \& Oliveira, C. J. F. (2017). Effects of short-term consumption of Morinda citrifolia (Noni) fruit juice on mice intestine, liver and kidney immune modulation. Food and Agricultural Immunology, 28(3), 528-542. https://doi.org/10.1080/09540105.2017.1306492

Corsini, E., \& can Loveren, H. (2015). Molecular immunotoxicology. Weinheim Wiley-VCH Verlag HmbH \& Co.

Diniz, M. F., Dourado, V. A., Silva, M. E., Pedrosa, M. L., Bezerra, F. S., \& Lima, W. G. (2013). Cigarette smoke causes changes in liver and spleen of mice newborn exposed during pregnancy. Journal of Cytology \& Histology, 4, 168. https://doi.org/10.4172/2157-7099.1000168

Dwijayanti, D. R., Djati, M. S., \& Rifa'i, M. (2015). Decreasing the expression level of macrophage cell, pro-inflammatory cytokines and NF- $\mathrm{B}$ using VipAlbumin in vitro. Asian Journal of Cell Biology, 10, 43-56. https://doi.org/10.3923/ajcb.2015.43.56

Fawcett, A. (2012). Animal research review panel guideline 22: guidelines for the housing of mice in scientific institutions. Orange, New South Wales: Animal Welfare Unit, NSW Department of Primary Industries.

Gamst, G., Meyers, L. S., \& Guarino, A. J. (2008). Analysis of variance designs A conceptual and computational approach with SPSS and SAS. New York: Cambridge University Press. https://doi.org/10.1017/CBO9780511801648

Gao, J., Lauer, F. T., Mitchell, L. A., \& Burchiel, S. W. (2007). Microsomal epoxide hydrolase is required for 7,12-dimethylbenz[a]anthracene (DMBA)induced immunotoxicity in mice. Toxicological Science, 98(1), 137-144. https://doi.org/10.1093/toxsci//kfm089

Gao, J., Mitchell, L. A., Lauer, F. T., \& Burchiel, S. W. (2008). p53 and TAM/ATR regulate 7,12-dimethylbenz[a]anthracene-induced immunosuppression. Molecular Pharmacoloy, 73(1), 137-146. https://doi.org/10.1124/mol.107.039230

Hong, Y. H., Yi, Y., Han, S. Y., Aziz, N., Kim, H. G., Park, S. H., Hossain, M. A., Baik, K. S., Choi, S. Y., Lee, J., Kim, J., \& Cho, J. Y. (2019). Morinda citrifolia noni water extract enhances innate and adaptive immune responses in healthy mice, ex vivo, and in vitro. Phytotherapy Research, 33(3), 676-689. https://doi.org/10.1002/ptr.6256

Hutchinson, E., Avery, A., \& Vandewoude, S. (2005). Environmental enrichment for laboratory rodents. ILAR Journal, 46(2), 148-161. https://doi.org/10.1093/ilar.46.2.148

Inada, A. C., Figueiredo, O. S., dos Santos-Eichler, R. A., Freitas, K. C., Hiane, P. A., de Castro, A. P., \& Guimarães, R. C. A. (2017). Morinda citrifolia Linn. (Noni) and its potential in obesity-related metabolic dysfunction. Nutrients, 9(6), 540. https://doi.org/10.3390/nu9060540

International Agency for Research on Cancer. (2004). IARC monographs on the evaluation of carcinogenic risks to humans: Tobacco smoke and involuntary smoking (Vol. 83). Lyon: International Agency for Research on Cancer.

Institute of Medicine (US) Subcommittee on Military Weight Management (2004). Weight managemnet: State of the science and opportunities for military program. Washington (DC): National Academies Press (US)

Juhász, K., Gombos, K., Szirmai, M., Gõcze, K., Wolher, V., Révész, P., Magda, I., Sebestyén, A., Németh, Á., \& Ember, I. (2013). Very early effect of DMBA and MNU on microRNA expression. In Vivo, 27, 113-118.

Kapila, V., \& Tuma, F. (2018). Physiology, spleen. Treasure Island: StatPearls Publishing.

Lee, J., Taneja, V., \& Vassallo, R. (2012). Cigarette smoking and inflammation Cellular and molecular mechanism. Critical Reviews in Oral Biology \& Medicine, 91(2), 142-149. https://doi.org/10.1177/0022034511421200

Li, A., Tanabe, S., Jiang, G., Giesy, J. P., \& Lam, P. K. S. (2007). Persistent organic pollutants in Asia: Sources, distributions, transport and fate. Amsterdam: Elsevier Ltd. https://doi.org/10.1016/s1474-8177(07)x0700-9

Li, Y., Yao, J., Han, C., Yang, J., Chaudhry, M. T., Wang, S., Liu, H., \& Yin, Y. (2016). Quercetin, inflammation and immunity. Nutrients, 8(3), 167.

McKoy, M. L., Thomas, E. A., \& Simon, O. R. (2002). Preliminary investigation of the anti-inflammatory properties of an aqueous extract from Morinda citrifolia (Noni). Proceedings of the Western Pharmacology Society, 45, 76-78.

Mensah, M. L. K., Komlaga, G., Forkuo, A. D., Firempong, C., Anning, A. K., \& Dickson, R. A. (2019). Toxicity and safety implications of herbal medicines used in Africa. In: Philip F. Burders (Ed.), Herbal medicine. US: IntechOpen. https://doi.org/10.5772/intechopen.72437

Michael, B., Yano, B., Sellers, R. S., Perry, R., Morton, D., Roome, N., Johnson, J. K., Schafer, K., \& Pitsch, S. (2007). Evaluation of organ weights for rodent and non-rodent toxicity studies: a review of regulatory guidelines and a survey of $\begin{array}{llll}\text { current practices. Toxicologic Pathology, 35(5), 742-750. } & \end{array}$ https://doi.org/10.1080/01926230701595292

Morgan, M. J., \& Liu, Z. (2011). Crosstalk of reactive oxygen species \& NF- $\kappa$ B signaling. Cell Research, 21, 103-115. https://doi.org/10.1038/cr.2010.178

Murata, K., Abe, Y., Futamura-Masuda, M., Uwaya, A., Isami, F., \& Matsuda, H (2014). Activation of cell-mediated immunity by Morinda citrifolia fruit extract and its constituent. Natural Product Communications, 9(4): 445-450. https://doi.org/10.1177/1934578x1400900401

Nayak, S., \& Mengi, S. (2010). Immunostimulant activity of noni (Morinda citrifolia) on $\mathrm{T}$ and lymphocytes. Pharmaceutical Biology, 48(7), 724-731. https://doi.org/10.3109/13880200903264434

Nelson, S. C., \& Elevitch, C. R. (2006). Noni: The complete guide for consumers and growers. Holualoa, Hawaii: Permanent Agriculture Resources.

Neta, R., Sayers, T. J., \& Oppenheim, J. J. (1992). Relationship of TNF to interleukins. Immunology Serum, 56, 499-566.

Nuryunarsih, D. (2016). Counterfeit Herbal Medicine adulterated with chemica drugs in Indonesia: NADFC Public warning 2011-2014. International Journal of Herbs, Spices and Medicinal Plants, 1(1), 002-017.

Ozturk, F., Ozturk, I. C., Batcioglu, K., \& Vardi, N. (2006). The effect of melatonin on 7,12-dimethyl-benz[a]anthracene injury in comparison with vitamin E + selenium in mouse kidneys. Fundamental \& Clinical Pharmacology, 20(4) 359-364. https://doi.org/10.1111/j.1472-8206.2006.00419.x 
Palu, A. K., Kim, A. H., West, B. J., Deng, S., Jensen, J., \& White, L. (2008) The effects of Morinda citrifolia L. (noni) on the immune system: its molecular mechanisms of action. Journal of Ethnopharmacology, 115(3), 502-506. https://doi.org/10.1016/j.jep.2007.10.023

Phaniendra, A., Jestadi, D. B., \& Periyasamy, L. (2015). Free radicals: properties, sources, targets, and their implication in various diseases. Indian Journal of Clinical Biochemistry, 30(1), 11-26. https://doi.org/10.1007/s12291-014-0446-0

Rifa'i, M., \& Widodo, N. (2014). Significance of propolis administration for homeostasis of $\mathrm{CD}^{+} \mathrm{CD} 25^{+} \mathrm{T}$ immunoregulatory cells controlling hyperglycemia. SpringerPlus, 2014(3), 526. https://doi.org/10.1186/2193-18013-526

Rubailo, A. I., \& Oberenko, A. V. (2008). Polycyclic Aromatic Hydrocarbons as priority pollutants. Journal of Siberian Federal University, 4(2008 1), 344-354.

Sahoo, H. B., Santani, D. D., \& Sagar, R. (2014). Chemopreventive potential of Apium leptophyllum (Pers.) against DMBA induced skin carcinogenesis model by modulatory influence on biochemical and antioxidant biomarkers in Swiss mice. Indian Journal of Phrmacology, 46(5), 531-537. https://doi.org/10.4103/02537613.140587

Sellers, R. S., Morton, D., Michael, B., Roome, N., Johnson, J. K., Yano, B. L., Perry, R., \& Schafer, K. (2007). Society of Toxicologic Pathology position paper: organ weight recommendations for toxicology studies. Toxicologic Pathology, 35(5), 751-755. https://doi.org/10.1080/01926230701595300

Shalan, N. A. A. M., Mustapha, N. M., \& Mohamed, S. (2017). Chronic toxicity evaluation of Morinda citrifolia fruit and leaf in mice. Regulatory Toxicology and Pharmacology, 83, 46-53. https://doi.org/10.1016/j.yrtph.2016.11.022

Shazia, R. C., \& Panuganti, K. K. (2019). Anatomy, abdomen and pelvis, spleen. Treasure Island: StatPearls Publishing.

Sholikhah, E. N. 2(016). Indonesian medicinal plants as sources of secondary metabolites for pharmaceutical industry. Journal of Medical Sciences, 48(4), 226 239. https://doi.org/10.19106/jmedsci004804201606

Stadlbauer, V., Fickert, P., Lackner, C., Schmerlain, J., Krisper, P., Trauner, M., \& Stauber, R. E. (2005). Hepatotoxicity of NONI juice: report of two cases. World Journal of Gastroenterology, 11(30), 4758-4760. https://doi.org/10.3748/wjg.v11.i30.4758

Stadlbauer, V., Weiss, S., Payer, F., \& Stauber, R. E. (2008). Herbal does not at all mean innocuous: The sixth case of hepatotoxicity associated with Morinda citrifolia (noni). The American Journal of Gastroenterology, 103(9), 2406-2407. https://doi.org/10.1111/j.1572-0241.2008.02010 8.x

Thamizharasi, G., Sindhu, G., Veeravarmal, V., \& Nalini, N. (2019). Preventive effect of C-carvone during DMBA induced mouse skin tumorigenesis by modulating xenobiotic metabolism and induction of apoptotic events. Biomedicine \& Pharmacotherapy, 111, 178-187. https://doi.org/10.1016/j.biopha.2018.12.071

Wan, W. H., Morris, A., Kinnear, G., Pearce, W., Mok, J., Wyss, D., \& Stevenson, C. S. (2010). Pharmacological characterization of anti-inflammatory compounds in acute and chronic mouse models of cigarette-induced inflammation. Respiratory Research, 11(1), 126. https://doi.org/10.1186/14659921-11-126

Wang, M. Y., Diane, N., Gary, A., Jarakae, J., \& West, B. (2008). Liver protective effects of Morinda citrifolia (noni). Plant Foods for Human Nutrition, 63(2), 59-63. https://doi.org/10.1007/s11130-008-0070-3

West, B. J., Jensen, C. J., Westendorf, J., \& White, L. D. (2006). A safety review of noni juice fruit. Journal of Food Science, 71(8), 100-106. https://doi.org/10.1111/j.1750-3841.2006.00164.x

West, B. J., Su, C. X., \& Jensen, C. J. (2009a). Hepatotoxicity and subchronic toxicity tests of Morinda citrifolia (noni) fruit. The Journal of Toxicological Science, 34(5), 581-585.

West, B., White, L. D., Jensen, C. J., \& Palu, A. K. (2009b). A double-blind clinical safety study of noni fruit juice. Pacific Health Dialog, 15(2), 21-32.

Yarosz, E. L., \& Chang, C. (2018). The role of reactive oxygen species in regulating T cell-mediated immunity and disease. Immune Network, 18(1), e14. https://doi.org/10.4110/in.2018.18.e14

Yang, X., \& Xu, T. (2011). Molecular mechanism of size control in development and human diseases. Cell Resarch, 21(5), 715-729. https://dx.doi.org/10.1038\%2Fcr.2011.63

Yatim, K. M., \& Lakkis, F. G. (2010). A brief journey through the immune system. Clinical Journal of the American Society of Nephrology, 10, 1274-1281. 